\title{
OPEM
}

www.opem.org

Oriental Pharmacy and Experimental Medicine 2008 7(5), 534-539

DOI 10.3742/OPEM.2008.7.5.534

\section{Protective effect of Shenqi-wan and its fractions on $N$-methyl-D-aspartate- induced excitotoxicity in rat hippocampus}

\author{
Joung-Hun Lee', Youn-Sub Kim¹, Young-Sick Kim², Sung-Eun Kim², Yun-Hee Sung ${ }^{2}$, Bo-Kyun Kim², \\ Jin-Woo Lee ${ }^{2}$, Dae-Hyun Ham ${ }^{3}$, Hyejung Lee ${ }^{3}$ and Chang-Ju Kim ${ }^{2,3, *}$ \\ ${ }^{1}$ Department of Anatomy-Pointology, College of Oriental Medicine, Kyungwon University, 65 Bokjung-dong, \\ Sujung-gu, Songnam 461-701, Republic of Korea; ${ }^{2}$ Department of Physiology, College of Medicine, Kyung Hee \\ University; ${ }^{3}$ Acupuncture and Meridian Science Research Center, Kyung Hee University, 1 Hoigi-dong, Dongdaemoon-gu, \\ Seoul 130-701, Republic of Korea
}

\begin{abstract}
SUMMARY
Shenqi-wan, Oriental herbal medicine formulation, has traditionally been used for the treatment of delayed mental and physical development in children, complications of diabetes, and glomerulonephritis. In the present study, we investigated the protective effect of the aqueous extract of Shenqi-wan and its fractions against $N$-methyl-D-aspartate (NMDA)-induced exitotoxicity in rat hippocampal CA1 neurons. Fractions were elucidated at $0-10 \mathrm{~min}, 11-20 \mathrm{~min}$, and $21-30 \mathrm{~min}$ by using gravity column chromatography method. In the present results, treatment with NMDA on cultured hippocampal slices induced neuronal death in the hippocampal CA1 region. Pretreatment with the Shenqi-wan did not exerted protective effect, however its fractions suppressed NMDA-induced neuronal damage. The fraction elucidated at 11 - 20 min showed the most potent protective effect. These results revealed that effective substances of the Shenqi-wan against NMDA-induced excitotoxicity may exist mainly in the fraction elucidated at $11-20 \mathrm{~min}$.
\end{abstract}

Key words: Shenqi-wan; Fractions; N-methyl-D-aspartate; Hippocampus; CA1 region

\section{ITRODUCTION}

Glutamate is major excitatory neurotransmitter and it has two types of receptors in the mammalian brain. One is ionotropic receptors divided $N$-methylD-aspartate (NMDA) receptors, $\alpha$-amino-3-hydroxy5-methylisoxazole-3-propionate (AMPA) receptors, and kainate (KA) receptors. They open glutamategated cation channels, and are subdivided into NMDA and non-NMDA by $\mathrm{Ca}^{2+}$ permeability. Another is metabotropic receptors (mGluRs), as G-

\footnotetext{
*Correspondence: Chang-Ju Kim, Department of Physiology, College of Medicine, Kyung Hee University, 1 Hoigidong, Dongdaemoon-gu, Seoul 130-701, Republic of Korea. Tel: +8229610407; Fax: +8229642195; E-mail: changju@khu.ac.kr
}

protein coupled receptors (Verkhratsky and Kirchhoff, 2007).

Ionotropic glutamate recepters play a crucial role in the pathology of cerebral ischemia and stroke (Andras et al., 2007). Because of decreased cerebral blood flow in ischemia and stroke, induces reduction of oxygen, finally ATP depletion and increase of extracellular glutamate. In this situation, ionotropic glutamate receptors induce excessive intracellular $\mathrm{Ca}^{2+}$ release that initiates several metabolic pathways, and leads to neuronal cell death, that is called 'excitotoxicity'. To reduce excitotoxicity, it was shown that ionotropic glutamate receptors antagonists exerted protective effect on neuronal cell death and also reduced brain edema induced by cerebral ischemia and 
intracerebral hemorrhage (Andras et al., 2007).

Shenqi-wan, an Oriental herbal formulation, is traditionally been used for the treatment of delayed mental and physical development in children, complications of diabetes, and glomerulonephritis patients (Wang and Zhang, 1987; Chen et al., 1997). However, the effect of Shenqi-wan on NMDAinduced excitotoxicity has not been reported yet. In the present study, the protective effects of the aqueous extract of Shenqi-wan and its fractions on NMDA-induced excitotoxicity were investigated using by organotypic rat hippocampal slice culture.

\section{MATERIAL AND METHODS}

\section{Preparation of the aqueous extract of Shenqi-wan} and its fractions

The ingredients of Shenqi-wan are as follows: Rehmanniae Radix 16 g, Dioscorae Radix 8 g, Corni Fructus 8 g, Alimatis Rhizoma 6 g, Moutan Cortex Radicis 6 g, Hoelen 6 g, Maximowicziae Fructus 8 g, and Cervi Cornu 4 g. All ingredients were obtained from the Kyung Dong marketplace (Seoul, Republic of Korea). After washing, to obtain the aqueous extracts of Shenqi-wan, the ingredients were added to distilled water, heat-extracted, pressure-filtered, concentrated with rotary evaporator, and lyophilized (EYELA, Tokyo, Japan). The resulting powder, weighing $15.48 \mathrm{~g}$ (a yield of $24.97 \%$ ) was diluted to the concentrations needed with distilled water and filtered through a $0.22 \mu \mathrm{m}$ syringe filter before use.

To obtain the fractions of lyophilized aqueous extraction of Shenqi-wan, gravity column chromatography method was used. In briefly, $5 \mathrm{~g}$ of lyophilized aqueous extraction of Shenqi-wan was dissolved with $5 \mathrm{ml}$ distilled water and loaded to $5 \mathrm{~cm}$ diameter glass column filled up about three forth with Diaion $^{\circledR}$ HP-20, mobile phase was distilled water. The fractions were collected at every 30 s used by Retriever ${ }^{\circledR} 500$, and terminated at $30 \mathrm{~min}$ after. The fractions were merged at 0 to $10 \mathrm{~min}$ (fraction 1), 11 to $20 \mathrm{~min}$ (fraction 2), and 21 to $30 \mathrm{~min}$ (fraction 3), and they were concentrated with rotary evaporator and lyophilized (EYELA, Tokyo, Japan). The resulting powders weighing $2.05 \mathrm{~g}$ (a yield of $41 \%$ ) in fraction1, $1.20 \mathrm{~g}$ (a yield of $24 \%$ ) in fraction 2, and $0.292 \mathrm{~g}$ (a yield of $5.84 \%$ ) in fraction 3 were diluted to the concentrations needed using distilled water, and filtered through a $0.22 \mu \mathrm{m}$ syringe filter before use.

\section{Organotypic slice culture}

Organotypic hippocampal slice culture was prepared by a previously described method (Lee et al., 2003). The hippocampi of Sprague-Dawley rats (postnatal day 7) were isolated and cut transversely at a thickness of $350 \mu \mathrm{m}$ using a McILWAIN tissue chopper (Mickle Laboratory Engineering Co., Surrey, UK). The slices were placed on MillicellCM inserts (Millipore) in 6 well plates that contained $1 \mathrm{ml}$ of culturing medium composed of $50 \%$ minimum essential media $\alpha$-modification ( $\alpha$-MEM), $25 \%$ Hank's balanced salts solution (HBSS) and $25 \%$ horse serum. The slices were cultured for 14 days at $36^{\circ} \mathrm{C}$ in a $5 \% \mathrm{CO}_{2}$ incubator, and the medium was changed every third day. This experiment was designed to investigate the protective effect of aqueous extraction of Shenqi-wan and its fractions on NMDA-induced hippocampal neuronal damage. The slice cultures were divided into 10 groups: the control group, the $10^{4} \mathrm{M}$ NMDA-treated group, the $0.1 \mathrm{mg} / \mathrm{ml}$ Shenqi-wan pre-treated and $10^{-4} \mathrm{M}$ NMDA-treated group, the $1 \mathrm{mg} / \mathrm{ml}$ Shenqi-wan pre-treated and $10^{-4} \mathrm{M}$ NMDA-treated group, the $0.1 \mathrm{mg} / \mathrm{ml}$ fraction 1 pre-treated and $10^{4} \mathrm{M}$ NMDAtreated group, the $1 \mathrm{mg} / \mathrm{ml} 0.1 \mathrm{mg} / \mathrm{ml}$ fraction 1 pre-treated and $10^{4} \mathrm{M}$ NMDA-treated group, the $0.1 \mathrm{mg} / \mathrm{ml}$ fraction 2 pre-treated and $10^{-4} \mathrm{M}$ NMDAtreated group, the $1 \mathrm{mg} / \mathrm{ml}$ fraction 2 pre-treated and $10^{-4} \mathrm{M}$ NMDA-treated group, the $0.1 \mathrm{mg} / \mathrm{ml}$ fraction 3 pre-treated and $10^{-4} \mathrm{M}$ NMDA-treated group, and the $1 \mathrm{mg} / \mathrm{ml}$ fraction 3 pre-treated and $10^{-4} \mathrm{M}$ NMDA-treated group. NMDA was treated for $48 \mathrm{~h}$ and aqueous extracts of Shenqi-wan and its fractions were pre-treated $1 \mathrm{~h}$ before the NMDA exposure in hippocampal slice cultures. 
Propidium iodide (PI, $5 \mathrm{mg} / \mathrm{ml}$ ) was added to each well and PI stained images were captured under same exposure using an inverted fluorescence microscope with an attached digital CCD camera (Axiovert S100, Zeiss, Göttingen, Germany). The observed areas were measured using the ImagePro ${ }^{\circledR}$ analysis software (version 1.52), and the percentage of neuronal death was then calculated.

\section{Drugs}

$\alpha$-MEM and HBSS used in this experiment were obtained from JBI (Daegu, Republic of Korea) and all other drugs used in this experiment were obtained from Sigma Chemical Co. (St. Louis, MO, USA).

\section{Statistics}

The results were presented as the mean \pm standard error of the mean (S.E.M.). Statistical analysis was made by one-way ANOVA followed by Duncan post-hoc test. The differences were considered significantly at $P<0.05$.

\section{RESULTS}

Effect of aqueous extract of Shenqi-wan on NMDA-induced neuronal damage

NMDA-induced neuronal damage in the pyramidal layer of the hippocampal CA1 region was visualized by PI staining, which is preferentially taken up into nonviable cells. In the control group, $4.1 \pm 1.6 \%$ of PI staining was observed. After $48 \mathrm{~h}$ of exposure to NMDA, the level of PI uptake was markedly increased, and most of the cells in the pyramidal layer of the hippocampal CA1 were stained with PI. PI uptake in the groups pre-treated with the aqueous extract of Shenqi-wan at the concentrations of $0.1 \mathrm{mg} / \mathrm{ml}$ and $1 \mathrm{mg} / \mathrm{ml}$ was $90.7 \pm 8.6 \%$ and $82.1 \pm 15.9 \%$, respectively. The present results showed that the aqueous extract of Shenqi-wan exerted no significant effect on NMDAinduced neuronal cell death in rat hippocampal CA1 region (Fig. 1).
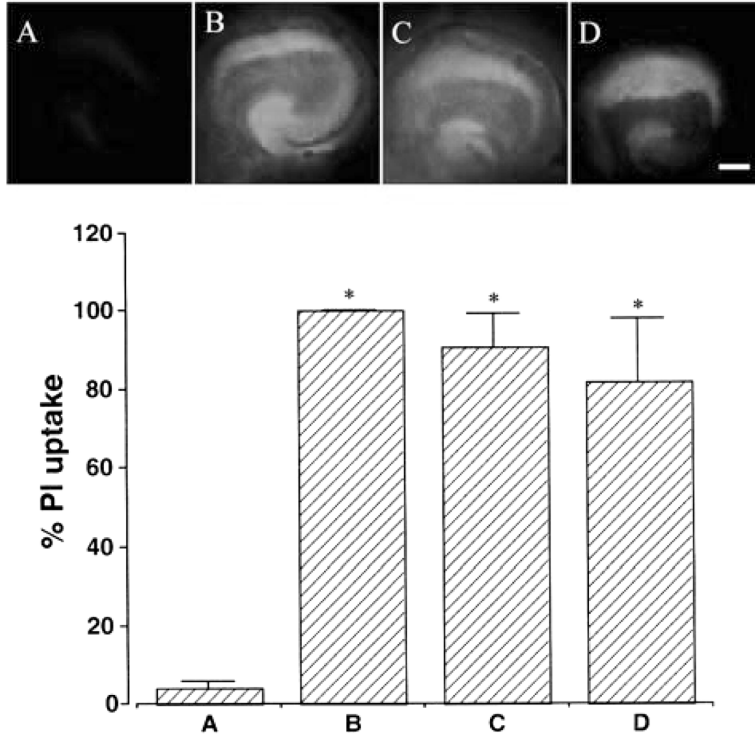

Fig. 1. Effect of Shenqi-wan on PI uptake in hippocampal slice culture. Upper: Photomicrographs of PI-assayed culture. The scale bar represents $400 \mu \mathrm{m}$. Lower: Level of PI staining in each group. (A) Control group, (B) $10^{-4} \mathrm{M}$ NMDA-treated group, (C) $0.1 \mathrm{mg} / \mathrm{ml}$ Shenqi-wan pre-treated and $10^{-4} \mathrm{M}$ NMDA-treated group, and (D) $1 \mathrm{mg} / \mathrm{ml}$ Shenqi-wan pre-treated and $10^{4} \mathrm{M}$ NMDA-treated group. The results are presented as mean \pm S.E.M. "represents $P<0.05$ compared to the control group.

Effect of the fraction 1 of Shenqi-wan on NMDAinduced neuronal damage

NMDA-induced neuronal damage in the pyramidal layer of the hippocampal CA1 region was visualized by PI staining, which is preferentially taken up into nonviable cells. In the control group, $4.1 \pm 1.6 \%$ of PI staining was observed. After $48 \mathrm{~h}$ of exposure to NMDA, the level of PI uptake was markedly increased, and most of the cells in the pyramidal layer of the hippocampal CA1 were stained with PI. PI uptake in the groups pre-treated with fraction 1 of Shenqi-wan at the concentrations of $0.1 \mathrm{mg} / \mathrm{ml}$ and $1 \mathrm{mg} / \mathrm{ml}$ was $94.2 \pm 6.2 \%$ and $94.8 \pm 8.6 \%$, respectively. The present results showed that the fraction 1 of Shenqi-wan exerted no significant effect on NMDA-induced neuronal cell death in rat hippocampal CA1 region (Fig. 2). 

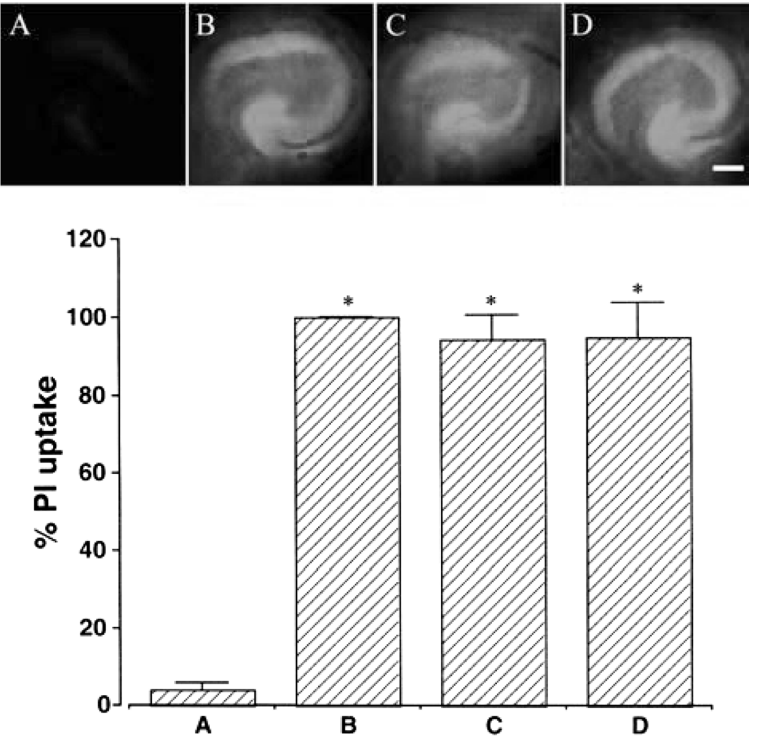

Fig. 2. Effect of fraction 1 of Shenqi-wan elucidated at 0-10 min on PI uptake in hippocampal slice culture. Upper: Photomicrographs of PI-assayed culture. The scale bar represents $400 \mu \mathrm{m}$. Lower: Level of PI staining in each group. (A) Control group, (B) $10^{-4} \mathrm{M}$ NMDA-treated group, (C) $0.1 \mathrm{mg} / \mathrm{ml}$ fraction 1 pretreated and $10^{4} \mathrm{M}$ NMDA-treated group, and (D) $1 \mathrm{mg} / \mathrm{ml}$ fraction 1 and $10^{-4} \mathrm{M}$ NMDA-treated group. The results are presented as mean \pm S.E.M. represents $P<0.05$ compared to the control group.

Effect of fraction 2 of Shenqi-wan on NMDAinduced neuronal damage

NMDA-induced neuronal damage in the pyramidal layer of the hippocampal CA1 region was visualized by PI staining, which is preferentially taken up into nonviable cells. In the control group, $4.1 \pm 1.6 \%$ of PI staining was observed. After $48 \mathrm{~h}$ of exposure to NMDA, the level of PI uptake was markedly increased, and most of the cells in the pyramidal layer of the hippocampal CA1 were stained with PI. PI uptake in the groups pre-treated with fraction 2 of Shenqi-wan at the concentrations of $0.1 \mathrm{mg} / \mathrm{ml}$ and $1 \mathrm{mg} / \mathrm{ml}$ was $58.4 \pm 6.7 \%$ and $38.4 \pm 11.6 \%$, respectively. The present results showed that fraction 2 of Shenqi-wan exerted protective effect on NMDA-induced neuronal cell death in rat hippocampal CA1 region as dose-dependant manner (Fig. 3).
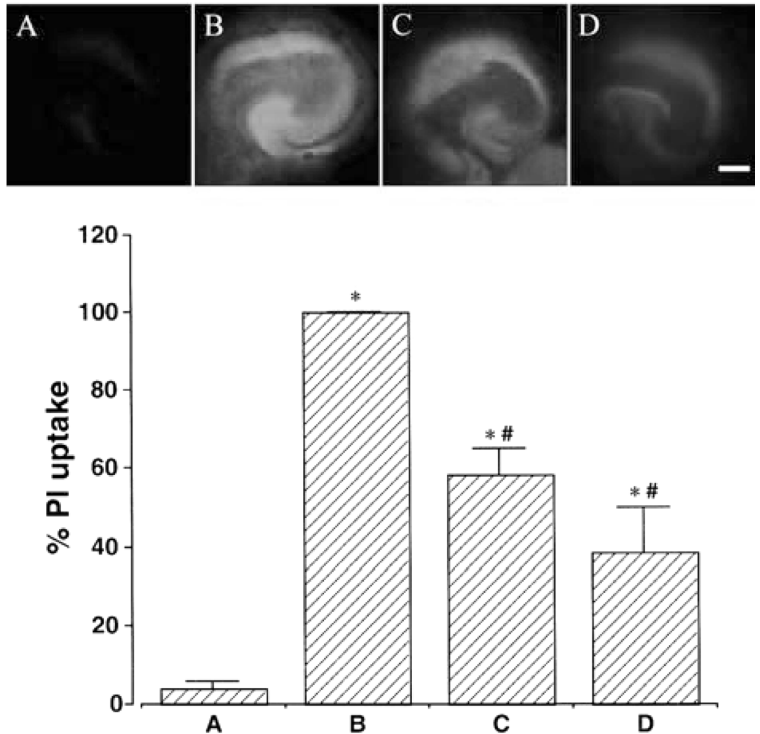

Fig. 3. Effect of fraction 2 of Shenqi-wan elucidated at 11 - 20 min on PI uptake in hippocampal slice culture. Upper: Photomicrographs of PI-assayed culture. The scale bar represents $400 \mu \mathrm{m}$. Lower: Level of PI staining in each group. (A) Control group, (B) $10^{-4} \mathrm{M}$ NMDA-treated group, (C) $0.1 \mathrm{mg} / \mathrm{ml}$ fraction 2 pretreated and $10^{-} \mathrm{M}$ NMDA-treated group, and (D) $1 \mathrm{mg} / \mathrm{ml}$ fraction 2 and $10^{-4} \mathrm{M}$ NMDA-treated group. The results are presented as mean \pm S.E.M. ${ }^{*}$ represents $P<0.05$ compared to the control group. " represents $P<0.05$ compared to the NMDA-treated group.

\section{Effect of fraction 3 of Shenqi-wan on NMDA-} induced neuronal damage

NMDA-induced neuronal damage in the pyramidal layer of the hippocampal CA1 region was visualized by PI staining, which is preferentially taken up into nonviable cells. In the control group, $4.1 \pm$ $1.6 \%$ of PI staining was observed. After $48 \mathrm{~h}$ of exposure to NMDA, the level of PI uptake was markedly increased, and most of the cells in the pyramidal layer of the hippocampal CA1 were stained with PI. PI uptake in the groups pre-treated with fraction 3 of Shenqi- at the concentrations of $0.1 \mathrm{mg} / \mathrm{ml}$ and $1 \mathrm{mg} / \mathrm{ml}$ was $88.4 \pm 6.1 \%$ and 55.8 $\pm 12.8 \%$, respectively. The present results showed that $1 \mathrm{mg} / \mathrm{ml}$ fraction 3 of Shenqi-wan exerted protective effect on NMDA-induced neuronal cell death in rat hippocampal CA1 region (Fig. 4). 

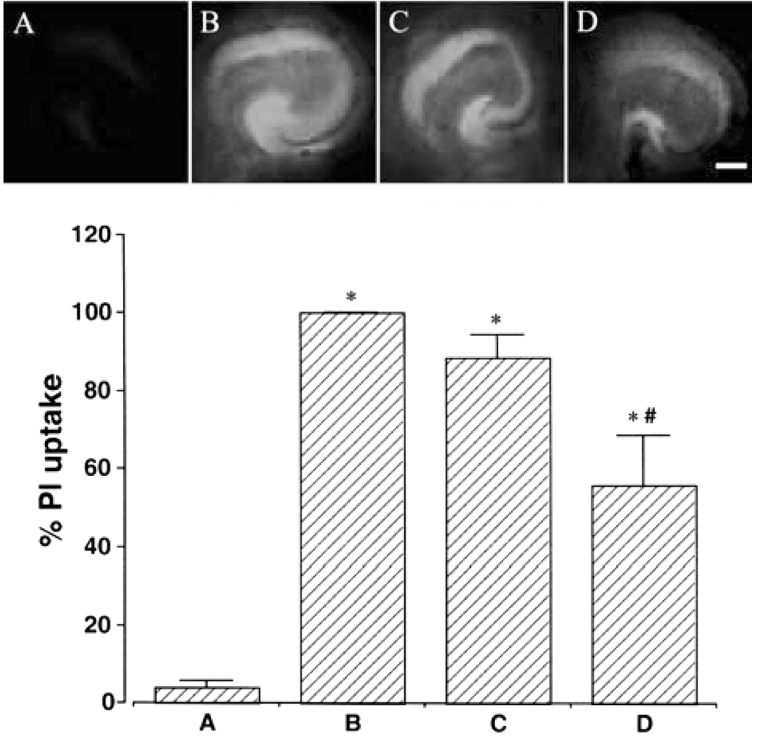

Fig. 4. Effect of fraction 3 of Shenqi-wan elucidated at 21 - 30 min on PI uptake in hippocampal slice culture. Upper: Photomicrographs of PI-assayed culture. The scale bar represents $400 \mu \mathrm{m}$. Lower: Level of PI staining in each group. (A) Control group, (B) $10^{-4} \mathrm{M}$ NMDA-treated group, (C) $0.1 \mathrm{mg} / \mathrm{ml}$ fraction 3 pretreated and $10^{-4} \mathrm{M}$ NMDA-treated group, and (D) $1 \mathrm{mg} / \mathrm{ml}$ fraction 3 pre-treated and $10^{-4} \mathrm{M}$ NMDAtreated group. The results are presented as mean \pm S.E.M. *represents $P<0.05$ compared to the control group. "represents $P<0.05$ compared to the NMDAtreated group.

\section{DISCUSSION}

In the present study, we compared the effects of the aqueous extract of Shenqi-wan and its fractions on NMDA-induced excitotoxicity in rat hippocampal CA1 region. In the present results, excitotoxicity induced by glutamate has been documented. It was reported that AMPA and KA receptors mediate ischemic damage in white matter axon (McCarran and Goldberg, 2007), and $\mathrm{Ca}^{2+}$ permeable AMPA channel contributed sporadic amyotrophic lateral sclerosis, Alzhemer's disease, and epilepsy (Kwak and Weiss, 2006). However, NMDA receptors and its effects are mainly targeted in exitotoxicity among the ionotropic glutamate subtype receptors. It is well known that hippocampal
CA1 region is more vulnerable to excitotoxicity compared to CA3 region, because of different existence of NMDA receptors response (Gee et al., 2006).

Increased extracellular concentration of glutamate overstimulates NMDA receptors resulting in increased $\mathrm{Ca}^{2+}$ influx, which in turn disables mitochondrial functions (Tong et al., 1995), rapidly increases the concentration of cytoplasmic reactive oxygen species (Gunasekar et al., 1995), and ultimately causes neuronal cell death. Because NMDA receptors play a crucial role in glutamateinduced acute neuronal damage, NMDA receptor antagonists are thought to reduce neuronal cell death during and following ischemic attacks (Simon et al., 1984).

Kim et al. (2007) showed the activation of protein kinase $\mathrm{C}$ through cyclooxygnase-2 (COX-2) pathway inducted neuroprotective effect on NMDA-induced ischemia, and $\mathrm{Xu}$ et al. (2007) suggested that NMDA receptors activated prosuvival pathway.

In the present results, the aqueous extract of Shenqi-wan at concentrations of $0.1 \mathrm{mg} / \mathrm{ml}$ and $1 \mathrm{mg} / \mathrm{ml}$ did not show significant protective effect on NMDA-induced exitotoxicity in rat hippocampal CA1 neurons. Shin et al. (2003) reported that Shenqi-wan has neuroprotective effect on $\mathrm{H}_{2} \mathrm{O}_{2}$ induced damage in HiB5 cell line and they also showed that this neuroprotective effect of Shenqiwan on exitotoxicity was induced by suppressing glutamate-activated and NMDA-activated ion currents in rat hippocampal CA1 neurons. Also Yang et al. (2006) reported that Liuweidihuang decoction, similar to Shenqi-wan, suppressed $\mathrm{K}^{+}$ and $\mathrm{Ca}^{2+}$ ion currents in cultured rat hippocampal neurons.

In the present study, we confirmed that the concentrations of the aqueous extract of Shenqi-wan used in this study exerted no significant neuroprotective effect on NMDA-induced excitotoxicity in rat hippocampal CA1 neurons. The fraction elucidated during 0-10 min also showed no significant protective effect. The 
fractions, however, elucidated during 11 - $20 \mathrm{~min}$ and during 21 - $30 \mathrm{~min}$ showed neuroprotective effect on NMDA-induced excitotoxicity. The fraction elucidated during $11-20$ min exerted most potent protective effect.

Here in this study, we suggest that the active substances for the neuroprotection of the aqueous extract of Shenqi-wan on NMDA-induced excitotoxicity in rat hippocampal CA1 neurons mainly exist in the fraction elucidated during 11-20 min. Additional studies on the effect of each ingredient herbs of Shenqi-wan and on the mechanism of this herbal formulation may yield novel ideas with possible implications for further therapeutic approaches.

\section{ACKNOWLEDGEMENTS}

This work was supported by the SRC/ERC program of MOST/KOSEF (R11-2005-014).

\section{REFERRENCES}

Andras IE, Deli MA, Veszelka S, Hayashi K, Hennig B, Toborek M. (2007) The NMDA and AMPA/KA receptors are involved in glutamate-induced alterations of occludin expression and phosphorylation in brain endothelial cells. J. Cereb. Blood Flow Metab. 27, 1431-1443.

Chen Y, Wei L, Ma M, Wu G, Zhang G and Wei Z. (1997) Effect of jiawei shenqi dihuang tang on the content of urinary protein in patients with diabetic nephrothy. J. Tradit. Chin. Med. 17, 184-186.

Gee CE, Benquet P, Raineteau O, Rietschin L, Kirbach SW, Gerber U. (2006) NMDA receptors and the differential ischemic vulnerability of hippocampal neurons. Eur. J. Neurosci. 23, 2595-2603.

Gunasekar PG, Kanthasamy AG, Borowitz JL, Isom GE. (1995) NMDA receptor activation produces concurrent generation of nitric oxide and reactive oxygen species, implication for cell death. $J$. Neurochem. 65, 2016-2021.

Kim E, Raval AP, Defazio RA, Perez-Pinzon MA.
(2007) Ischemic preconditioning via epsilon protein kinase $C$ activation requires cyclooxygenase-2 activation in vitro. Neuroscience 145, 931-941.

Kwak S, Weiss JH. (2006) Calcium-permeable AMPA channels in neurodegenerative disease and ischemia. Curr. Opin. Neurobiol. 16, 281-287.

Lee J, Son D, Lee P, Kim DK, Shin MC, Jang MH, Kim CJ, Kim YS, Kim SY, Kim H. (2003) Protective effect of methanol extract of Uncaria rhynchophylla against excitotoxicity induced by $N$-methyl-Daspartate in rat hippocampus. J. Pharmacol. Sci. 92, 70-73.

McCarran WJ, Goldberg MP. (2007) White matter axon vulnerability to AMPA/kainate receptormediated ischemic injury is developmentally regulated. J. Neurosci. 27, 4220-4229.

Shin HT, Chung SH, Lee JS, Kim SS, Shin HD, Jang MH, Shin MC, Bahn GH, Paik EK, Park JH, Kim CJ. (2003) Protective effect of Shenqi-wan against $\mathrm{H}_{2} \mathrm{O}_{2}$ induced apoptosis in hippocampal neuronal cells. Am. J. Chin. Med. 31, 675-686.

Simon RP, Swan JH, Griffiths T, Meldrum BS. (1984) Blockade of $N$-methyl-D-aspartate receptors may protect against ischemic damage in the brain. Science 226, 850-852.

Tong CM, Shepherd D, Jahr CE. (1995) Synaptic desensitization of NMDA receptors by calcineurin. Science 267, 1510-1512.

Verkhratsky A, Kirchhoff F. (2007) NMDA Receptors in glia. Neuroscientist 13, 28-37.

Wang J, Zhang DS. (1987) Effect of Shenqi-wan on immunological function in the nephrotic syndrome of chronic glomerulonephritis patients. Zhong Xi Yi Jie Za Zhi 7, 731-733.

Xu J, Zhang QG, Li C, Zhang GY. (2007) Subtoxic Nmethyl-D-aspartate delayed neuronal death in ischemic brain injury through TrkB receptor- and calmodulin-mediated PI-3K/Akt pathway activation. Hippocampus 17, 525-537.

Yang S, Zhou W, Zhang Y, Yan C, Zhao Y. (2006) Effects of Liuwei Dihuang decoction on ion channels and synaptic transmission in cultured hippocampal neuron of rat. J. Ethnopharmacol. 106, 166-172. 